\section{Discussion}

The present case shows some of the classical features of Noonan's syndrome-that is, short stature, pterygium colli, low set ears, ptosis, pectus excavatum, kyphoscoliosis, cubitus valgus, intellectual impairment, and delayed puberty. ${ }^{2}$ The syndrome is delineated principally at the clinical level and the combination of features suggests the diagnosis. Nevertheless, the findings of numerous cafe au lait spots in appropriate size and number established the diagnosis of von Recklinghausen's neurofibromatosis. The coexistence of both syndromes in one patient confirmed the diagnosis of neurofibromatosis-Noonan's syndrome. ${ }^{4-6}$

The term neurofibromatosis-Noonan's syndrome was coined in 1985 by Opitz et al, who suggested the syndrome to be a nosologically discrete, real biological entity of unknown aetiology. ${ }^{4}$ Although they believed neurofibromatosis-Noonan's syndrome to be fairly common, ${ }^{4}$ only a few such patients have been reported, and those reported had multiple cafe au lait spots and a phenotypic appearance appropriate for Noonan's syndrome. They seemed to have few or no Lisch nodules. Boys were more likely to have fusiform swelling of nerve strands, while girls tended to show the classical cutaneous neurofibromata. The reported cases as well as that reported by us may point toward two additional important diagnostic findings. The patients reported so far have been single cases with no familial incidence. It seems that the incidence of cardiac anomalies in these patients is low. In only one patient was there an appreciable systolic murmur; the echocardiogram, however, yielded normal results in this patient.
The aetiology of neurofibromatosis-Noonan's syndrome is not known. The possibility that both Noonan's syndrome and von Recklinghausen's neurofibromatosis occurred coincidentally in one patient is real, but most likely has a very low incidence. On the other hand, it may be suggested that these cases represent a separate genetic condition caused by a mutation at a locus that is different from either the neurofibromatosis or the Noonan's syndrome loci; alternatively, the Noonan's syndrome and neurofibromatosis loci may be close together on the same chromosome and the neurofibromatosis-Noonan's syndrome may be caused by a simultaneous mutation at both loci (probably a submicroscopic chromosome deletion). It seems that more reports of such patients are needed to learn the full extent of the clinical presentation of neurofibromatosis-Noonan's syndrome.

\footnotetext{
References

${ }^{1}$ Riccardi VM. Von Recklinghausen neurofibromatosis. N Engl J Med 1981;305:1617-26.

2 Mendez HM. Opitz JM. Noonan syndrome; a review. Am J Med Genet 1985;21:493-506.

${ }^{3}$ Goodman RM, Gorlin RJ. The malformed infant and child. New York and Oxford: Oxford University Press, 1983:408-9.

${ }^{4}$ Opitz JM, Weaver DD. The neurofibromatosis-Noonan syndrome. Am J Med Genet 1985;21:477-90.

${ }^{5}$ Mendez HMM. The neurofibromatosis-Noonan syndrome. Am J Med Genet 1985;21:471-6.

${ }^{6}$ Allanson JE, Hall JG, Van Allen MI. Noonan phenotype associated with neurofibromatosis. Am J Med Genet 1985;21:457-62.
}

Correspondence to Dr A Shuper, Department of Pediatrics B, Beilinson Medical Center, Petach Tikva, 49100, Israel.

Received 8 August 1986

\title{
Hydrops fetalis due to abnormal lymphatics
}

\author{
K P WINDEBANK, N A BRIDGES, I OSTMAN-SMITH, AND J E STEVENS
}

Department of Paediatrics, John Radcliffe Hospital, Oxford

SUMMARY A case of generalised lymphatic abnormality that presented with hydrops fetalis is described. This seems to be the first such case reported.

The reported incidence of non-immunological hydrops fetalis varies from one in $1400^{1}$ to one in
$7143 .^{2}$ Causes are identified in $56 \%^{3}$ to $85 \%^{1}$ of cases, among which cardiac arrhythmia, thalassaemia, twin to twin transfusion, and congenital heart disease account for half. ${ }^{3}$ Localised lymphatic abnormalities - that is, cystic hygroma, pulmonary lymphangectasia, ${ }^{24}$ and prolonged chylous ascites ${ }^{2}$ - may be causes, but there are no reports of generalised lymphatic abnormalities being associated with hydrops. 
The parents were unrelated members of a vagrant family. The mother was a heavy smoker (40 a day) and had attended antenatal clinic only once, at which time polyhydramnios was noted. At 34 weeks she went into spontaneous labour and a hydropic, female infant weighing $3410 \mathrm{~g}$ with a grossly oedematous placenta was delivered vaginally. The child required immediate intubation and ventilation but did not appear pale, and auscultation of the praecordium was normal with no tachycardia.

The mother's blood group was A Rh-positive and the baby's $\mathrm{O}$ Rh-positive with a negative direct Coombs test. The baby's haemoglobin concentration was $14.9 \mathrm{~g} / \mathrm{dl}$, total white blood cell count $16.6 \times 10^{9} / 1$, and platelets $202 \times 10^{9} / 1$, with a normal film. Biochemical values were normal except for an albumin concentration of $22 \mathrm{~g} / \mathrm{l}$ (normal $35-50 \mathrm{~g} / \mathrm{l}$ ), plasma osmolality $268 \mathrm{mOsm} / \mathrm{kg}$ (normal 289-308 $\mathrm{mOsm} / \mathrm{kg}$ ), and IgG $4.9 \mathrm{~g} / \mathrm{l}$ (normal 7-19 g/l). There was no proteinuria. Subsequently, the chromosomes were found to be normal, and there was no serological evidence of congenital infection. A chest radiograph showed a normal heart and small pleural effusions. The electrocardiogram yielded normal results and echocardiography showed a structurally normal heart with mild ventricular dysfunction.

Treatment was started with digoxin, diuretics, and salt poor albumin. By day 3 her bilirubin concentration had reached $300 \mu \mathrm{mol} / \mathrm{l}$ (normal 1-17 $\mu \mathrm{mol} / \mathrm{l}$ ) and a two volume exchange transfusion was performed. On day 5 her urine output decreased, her plasma urea rose to $22 \mathrm{mmol} / \mathrm{l}$ (normal $2 \cdot 5-8 \cdot 0$ $\mathrm{mmol} / \mathrm{l})$, and peritoneal dialysis was started. The plasma albumin concentration was $26 \mathrm{~g} / \mathrm{l}$ but her oedema did not improve and a sample of lower limb tissue fluid had an albumin concentration of $19 \mathrm{~g} / \mathrm{l}$. Her haemoglobin concentration fell to $5.9 \mathrm{~g} / \mathrm{dl}$ with no evidence of haemolysis or haemorrhage, but she did develop a generalised, blue skin discoloration.

The oedema slowly decreased, revealing small blue variceal vessels in both groins, and it became possible to insert a left internal jugular venous line and remove her umbilical lines. A sample taken from this line had a haemoglobin concentration of 3 $\mathrm{g} / \mathrm{dl}$. Clinically, this was very unlikely and samples were taken from the groin vessels and a scalp vein, which showed haemoglobin concentrations of 1.7 and $12.9 \mathrm{~g} / \mathrm{dl}$, respectively. These bizarre results suggested an anomaly of venous development and contrast studies were performed.

Niopam was injected into the left inguinal region and delineated a group of large vessels (Fig. 1). Contrast spread down the left leg and then across the lower abdomen filling smaller, superficial ves- sels. Large, deep vessels were then outlined in the right leg and finally the contrast spread up the right abdominal wall and stopped in blind ending vessels in the right axilla. Figure 2 shows the spread of contrast from the 'internal jugular line', delineating a large vessel in the middle, which disappears at the level of the fourth lumbar vertebra.

${ }^{99 \mathrm{~m}} \mathrm{Tc}$ labelled red cells were injected into the scalp vein and after two hours a normal blood pool was seen. By 12 hours there was excessive activity in the lower half of the body, suggesting abnormal accumulation of cells. Counts on the fluid from the groin vessels were initially high and fell gradually over 24 hours. These results suggested a major degree of communication between the abnormal vessels and the venous system.

By 3 weeks of age her albumin concentration was $40 \mathrm{~g} / \mathrm{l}$ and she had improved markedly with only

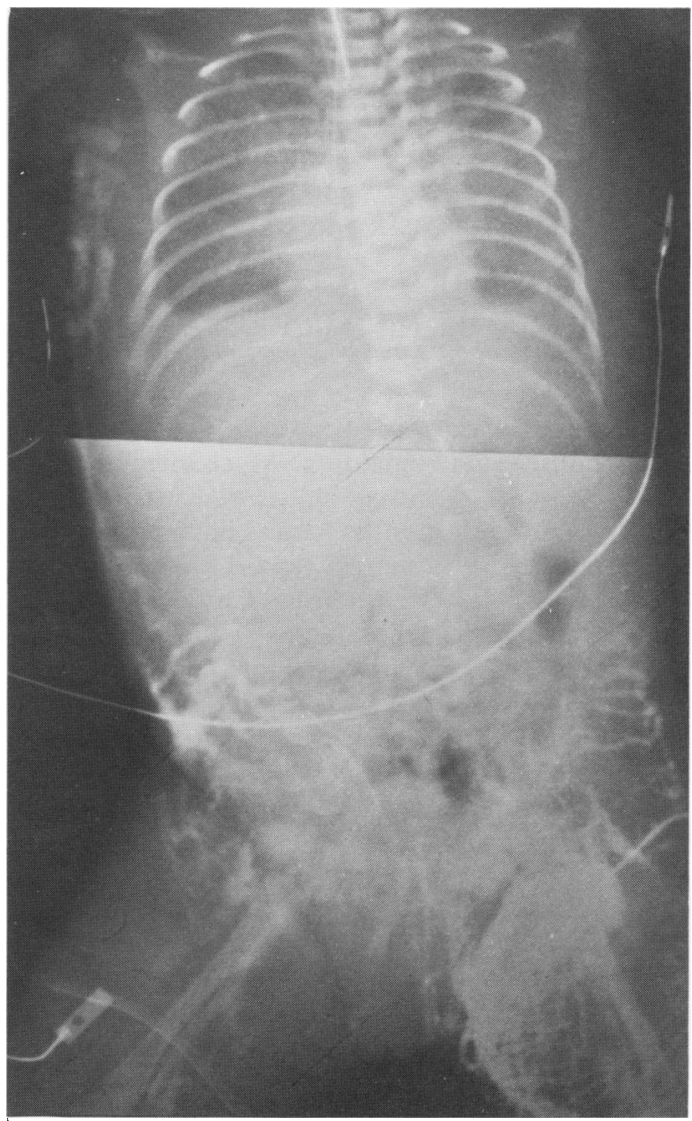

Fig. 1 Contrast injection into left groin, showing abnormal vessels ending blindly by the right axilla. (Composite figure from two radiographs.) 


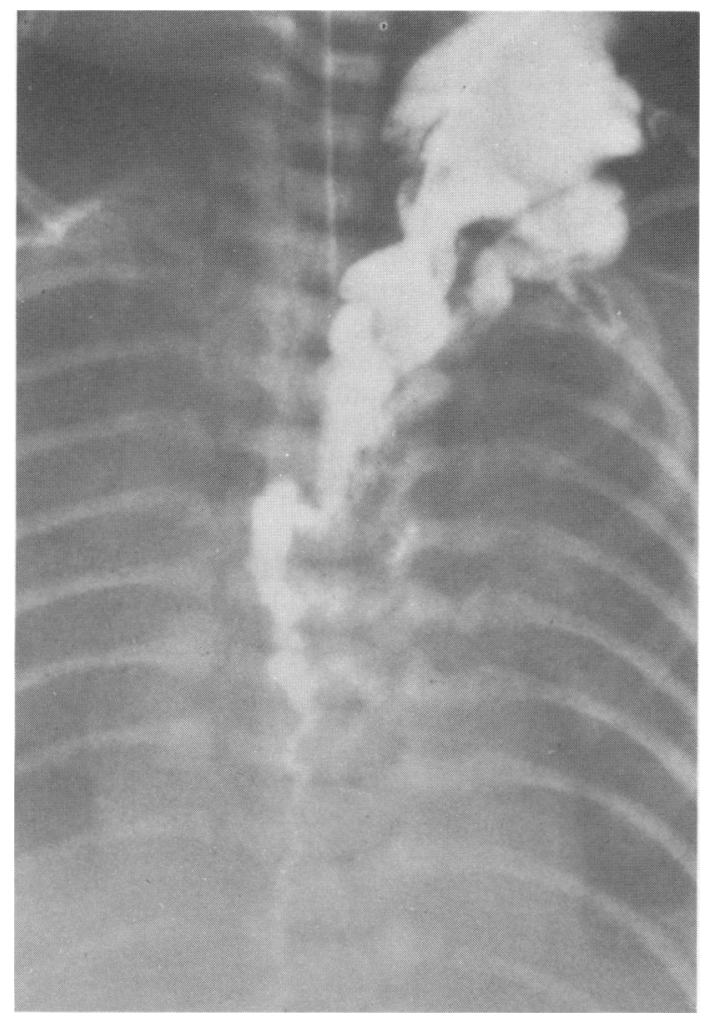

Fig. 2 Contrast injection into left 'internal jugular line'.

slight limb oedema remaining. Mechanical ventilation was stopped, oral feeding started, and she was discharged. One month later her generalised oedema recurred and she developed pneumonia and required mechanical ventilation. Chylous fluid was obtained from the subcutaneous tissues of all four limbs and the pleural spaces. Her plasma albumin concentration was $26 \mathrm{~g} / \mathrm{l}$. Renal failure developed and she died aged 66 days. Permission for a postmortem examination was refused.

\section{Discussion}

The radiological appearance of these vessels was neither typically lymphatic nor venous and probably reflected a shared developmental failure of the two systems. When enterally fed the child had an abnormal accumulation of chyle in the limbs and body cavities. It would therefore seem reasonable to classify this abnormality as a primary lymphatic deformity of mixed vascular type with abnormal chylous flow. ${ }^{5}$

Conventionally, the causes of hydropic oedema are described as anaemia, heart failure, and hypoproteinaemia or low colloid osmotic pressure. Barnes, however, pointed out that these conditions can exist in extreme forms without causing oedema and that therefore the mechanisms are more complex. $^{6}$

In this case we found an extremely high concentration of albumin in the extracellular fluid and it was only when the plasma albumin had risen to 40 $\mathrm{g} / \mathrm{l}$ that the baby's generalised oedema improved. As a result of the abnormal chylous flow, however, the child could not maintain its intravascular albumin when enterally fed and was re-admitted with a recurrence of generalised oedema. It seems likely, therefore, that the disturbed balance between intravascular and extravascular albumin due to the hybrid nature of the lymphatic and venous systems played an important part in the original hydropic appearance, independently of simple, mechanical lymphatic obstruction.

We thank Mrs A Osborne and Miss J Rackstraw for their help in preparing this manuscript.

\section{References}

1 Iliff PJ, Nicholls JM, Kecling JW, Gough JD. Non-immunologic hydrops foetalis: a review of 27 cases. Arch Dis Child 1983;58:979-82.

2 Etches PC, Lemmons JA. Nonimmune hydrops foctalis: report of 22 cases including three siblings. Pediatrics 1979;64:326-32.

${ }^{3}$ Turkel SB. Conditions associated with non-immune hydrops foctalis. Clin Perinatol 1982;9:613-25.

${ }^{4}$ Hutchison AA, Drew JA. Yu VYH, Williams ML, Fortune DW, Beischer NA. Non-immunologic hydrops foetalis: a review of 61 cases. Obstet Gynecol 1982;59:347-52.

${ }^{5}$ Kinmonth JB. The lymphatics. 2nd ed. London: Edward Arnold, 1982.

"Barnes SE, Bryan EM, Harris DA, Baum JD. Oedema in the newborn. In: Baum H, Gergely J, eds. Molecular aspects of medicine. Oxford: Pergamon, 1977:187-282.

Correspondence to Dr K Windebank, Department of Pediatrics, Mayo Clinic, Rochester, Minnesota, MN 559()5. United States of America.

Received 23 September 1986 